\title{
A RELAÇÃO SOCIEDADE E NATUREZA NA TRANSFORMAÇÃO DA PAISAGEM URBANA NO PROCESSO DE VERTICALIZAÇÃO NO BAIRRO DO HIPÓDROMO, RECIFE-PE
}

\author{
THE RELATION SOCIETY AND NATURE IN THE TRANSFORMATION OF THE \\ URBAN LANDSCAPE IN THE VERTICAL PROCESS IN THE HIPÓDROMO \\ NEIGHBORHOOD, RECIFE - PE
}

Áurea Nascimento de SIQUEIRA ${ }^{1}$, André dos SANTOS ${ }^{2}$, André Felipe de Oliveira SILVA ${ }^{3}$, Tiago Fernando de HOLANDA $^{4}$, Valéria Sandra de Oliveira COSTA ${ }^{5}$

Palavras-chave: Ambiente, Impactos ambientais, Áreas verdes, Verticalização

Keywords:

Environment, Environmental Impacts, Green Areas, Verticalization

\section{RESUMO}

As transformações da paisagem urbana vêm contribuindo para uma nova conjuntura estrutural dentro do espaço urbano. O bairro do Hipódromo, localizado na cidade do Recife, inserida na Região Metropolitana do Recife - RMR, tornou-se uma Zona Especial de Preservação do Patrimônio Histórico - Cultural (ZEPH), de acordo com a legislação de conservação desde 1979. Diante disto, o objetivo desta pesquisa, é analisar a relação sociedade e natureza na produção do espaço através da transformação no bairro do Hipódromo, contribuindo para compreender o processo de verticalização inicial através das transformações territoriais dentro desse ambiente. Neste caso, a complexidade diante do espaço e das transformações implica em uma produção social que se mercantiliza através do capital que gerencia os espaços urbanos, através dos elementos da paisagem, que predomina a desigualdade social, através da conjuntura instalada entre o ambiente e a qualidade de vida.

\section{ABSTRACT / RESUMEN / RÉSUMÉ / RIASSUNTO}

The transformations of the urban landscape have contributed to a new structural conjuncture within the urban space. The Hipódromo neighborhood, located in the city of Recife, inserted in the Metropolitan Region of Recife - RMR, has become a Special Area for the Preservation of Historical - Cultural Heritage (ZEPH), in accordance with the conservation legislation since 1979. Given this, the objective of this research is to analyze the relationship between society and nature in the production of space through transformation in the Hipódromo neighborhood, contributing to understand the process of initial verticalization through territorial transformations within that environment. In this case, the complexity in the face of space and transformations implies a social production that is commercialized through the capital that manages urban spaces, through the elements of the landscape, which prevails social inequality, through the conjuncture between environment and quality of life.

\footnotetext{
${ }^{1}$ Mestra em Desenvolvimento e Meio Ambiente - PRODEMA - Universidade Federal de Pernambuco (UFPE). E-mail: aurea.ans@gmail.com.

${ }^{2}$ Mestre em Ensino de Ciências Ambientais - Universidade Federal de Pernambuco (UFPE). E-mail: biologistsantosandre@gmail.com.

${ }^{3}$ Graduando em Licenciatura em Geografia - Universidade Federal de Pernambuco (UFPE). E-mail: andregjg@gmail.com

${ }^{4}$ Mestre em Ciências Geodésicas e Tecnologias da Geoinformação - Universidade Federal de Pernambuco (UFPE).

E-mail: tiagofholanda@gmail.com.

5 Professora Colaboradora CAPES/PNPD-PRODEMA-UFPE e Professora do PROFCIAMB-UFPE. E-mail: costavso@yahoo.com.br
} 


\section{INTRODUÇÃO}

A produção do espaço através das constantes transformações da paisagem urbana está inteiramente ligada ao processo, social, cultural, político e principalmente econômico. O espaço urbano torna-se mercadoria, através do seu valor de troca, acompanhado por interesses de áreas que apresentam condições e qualidade de vida, assim a paisagem se transforma, ganhando novas cores, matizes e novos elementos e é reproduzida de acordo com as conveniências humanas (Carlos, 2013).

A paisagem urbana varia de acordo com as necessidades existentes pela sociedade na produção do espaço. Nesse processo surgem elementos fundamentais da paisagem que diz respeito ao espaço, sendo reproduzido de forma desigual. Porém existem locais em que predominam as áreas verdes, arborizadas, de interesse econômico elevado que promove a utilização e práticas de conservação da natureza no processo de desenvolvimento urbano (Mazzei et al., 2007).

Neste aspecto, a natureza é utilizada em benefício da sociedade, e é considerada produto social em prol do capital. A produção do espaço é atendida para o modo de produção capitalista, onde a paisagem urbana se sobrepõe aos ambientes naturais pelas mudanças e necessidades da sociedade, sendo necessário um planejamento urbano que considere os fatores naturais, pois quando os espaços não são projetados para serem adequados a esses fatores, podem interferir na qualidade ambiental das cidades (Mendonça, 2004).

De modo que, com o aumento do processo de urbanização o ambiente natural começa a se extinguir, surgindo novos padrões de vida acompanhados pelas mudanças na conjuntura das cidades. Essas mudanças trazem na paisagem marca da história na produção da articulação entre o novo e o velho (Carlos, 2013).

A produção do espaço fica valorizado pelo solo urbano enquanto mercadoria, que se transforma através das técnicas, tornando a paisagem artificial (Santos, 2001). Nesse processo surgem grandes centros urbanos, indústrias, comércios, hospitais, escolas, tudo em prol do crescimento para atender as necessidades dos seres humanos em um espaço totalmente modificado. A população começa a crescer e os centros urbanos não têm mais espaços para se expandir, surgindo novas necessidades de moradia. Diante dessa situação, a verticalização do espaço urbano e acompanhado por mudanças na infraestrutura da cidade.

Neste contexto, a transformação da paisagem urbana na cidade do Recife no estado de Pernambuco, foi modificada ao longo de sua história, entre os fatores que contribuíram para esse fato, é importante mencionar as relações sociais de interesse do uso do solo urbano como mercadoria entre as relações que estabelecem na sociedade capitalista, como um conjunto de condições voltadas para aumento da qualidade de vida, onde as áreas que apresentam "bairrosjardins", (predominância de verde), são ambientes de interesse capitalista e da própria sociedade que procura condições de vida melhor nos grandes centros urbanos (Barbosa \& Júnior, 2009).

Neste sentido, a temática surgiu através do interesse em estudos voltados para relação sociedade e natureza, através da transformação da paisagem urbana, ocasionado pelo crescimento econômico de áreas 
que apresentam interesses dos empreendimentos imobiliários e benefícios para a população que procura qualidade de vida.

Grandes empreendimentos imobiliários beneficiarão parte da população com alto poder aquisitivo de uma determinada classe hegemônica, que ocuparam os supernos espaços urbanos através da lógica da valorização e consumo na cidade, que através das transformações o preço do uso do solo promovido pela ação do estado são usufruídas pelos especuladores, quando existe a possibilidade de antecipar a posse desses lugares em que as diversas redes de serviços serão aumentadas (Maricato, 1982).

Sendo assim, a conjuntura do planejamento urbano, tende a divergir a perspectiva da realidade da população suscetível, que se parece como ferramenta estratégica para reprodução do capital, decorrente da valorização da terra urbana, sendo assim capaz de tornar à terra aprazível aos olhares dos empreendedores e agir, com a produção e valorização dos imóveis, tornando-as "ilhas" de amenidades, dado encadeamento para novas especulações imobiliárias dentro da cidade (Gomes \& Albuquerque, 2013). Desta forma, a cidade torna-se atrativo como instrumento de valorização do capital através da venda e consumo do espaço urbano, dilatando a desigualdade social, sobrepondo o econômico como supremacia ao direito difuso da sociedade.

Diante deste contexto, é relevante a pesquisa para o aprofundamento e compreensão das relações sociedade e da natureza no processo de valorização e transformação da paisagem urbana pelo processo de verticalização. Entretanto é preciso ir mais além e questionar a complexidade existente dentro do cenário de transformação e envolvendo os conflitos diante da produção do espaço em benefício do capital imobiliário, e a relação sociedade e natureza presente nesta transformação na cidade do Recife-PE, surgindo os seguintes questionamentos: i) Quais as transformações da paisagem urbana no processo de produção do espaço? ii) Quais os conflitos sociais e ambientais decorrentes da verticalização da cidade do Recife-PE? iii) Quais espaços urbanos que estão sendo ocupados para a transformação da paisagem urbana? Perante as questões surgem às conjecturas que defende e afirma a relevância diante da temática exposta.

Diante do mencionado, a pesquisa tem como objetivo, analisar a relação sociedade e natureza na produção do espaço através da transformação no bairro do Hipódromo, Recife-PE, sendo possível compreender, o processo de verticalização que está em processo inicial através das transformações territoriais dentro desse ambiente.

\section{ESPAÇO COMO MODO DE PRODUÇÃO SOCIAL}

O espaço é explicado como produção social, sendo construído e materializado no processo de contradição, o espaço outrora natural ganha características determinadas, imposta pela produção desse espaço totalmente modificado, transformando a natureza em artificial (Santos, 2001).

O conceito de espaço surge através das indagações em relação à reprodução social no sentido da organização do espaço, contextualizando a partir das lutas de classes decorrentes da expansão capitalista. 
Neste contexto a produção do espaço percebe a partir da reflexão da dialética, ocasionando vários fatores decorrentes da luta de classe, que de acordo com Uriarte \& Carvalho $(2014$, p. 31) "o espaço está sempre sendo feito, porque ele é um conjunto de relações sociais - sempre dinâmicas - que se estabelecem numa materialidade (ou natureza primeira). Isto quer dizer que o espaço não é uma coisa, mas um conjunto de relações entre coisas"

Smith (1988), ressalta que as relações espaciais são geradas através da lógica, porém tornam-se dialetizadas, devido à atividade do ser humano no espaço e sobre ele, e neste espaço dialetizado de conflitos produz a reprodução sendo integrada em múltiplas contradições no espaço.

O espaço enquanto produção social produz condição para que as transformações sociais, políticas e econômicas, sejam materializadas no âmbito do espaço. Sendo assim, é condicionado para realização humana, como práxis sociais na construção de circunstância propícia. Neste aspecto Carlos (2011), compreende que a produção do espaço surge como inesperadamente à produção social que constitui a civilização.

$\mathrm{Na}$ transformação do espaço em prol do social, traz a reflexão sobre a produção do espaço sendo importante a realidade que foi construída no decorrer do processo histórico, o espaço foi sendo apropriado de acordo com os interesses sociais de cada momento. Neste sentido, torna-se um produto histórico que passa por mudanças produzidas pelas necessidades e exigências do modo de produção capitalista. A partir do modo de produção, a transformação do espaço natural torna cada vez mais materializada e requer uma nova conjuntura do espaço, sendo reconstruído através da produção social que resulta a produção e reprodução das relações sociais (Lefebvre, 2008).

Portanto, é de suma importância salientar que esse espaço produzido pelo homem, sofre modificações através do trabalho, que supre necessidades se oferece condições no processo de desenvolvimento para sobrevivência. Neste sentido, é importante compreender a relação do trabalho como meio indispensável para existência humana, efetivando a reciprocidade entre o homem e a natureza, para a manutenção da vida humana (Marx, 2008).

O trabalho é essencial para atender as demandas sociais inseridas no espaço, pois o espaço produz e garante o desenvolvimento das relações, ao longo do processo histórico, sendo assim, de acordo com Lima e Conceição (2010), a produção espacial, inserida no âmbito do conteúdo das relações sociais em um determinado período é, contudo, ontológica ao ser social.

O espaço está diretamente relacionado à produção das relações sociais construídas, para entendê-lo é necessário considerar a relação do trabalho e do capital, que define e produz o espaço, modificando a natureza. Deste modo evidencia a transformação decorrente das necessidades sociais e do sistema capitalista que rege a relação entre a sociedade na natureza. 


\section{A TRANSFORMAÇÃO DA PAISAGEM URBANA}

A paisagem permite analisar o espaço, considerando seus aspectos naturais e sociais presentes, tecendo e interagindo de forma harmônica. Segundo Santos (2004, p. 67) "Tudo o que nós vemos, o que nossa visão alcança, é a paisagem. Esta pode ser definida como o domínio do visível, aquilo que a visão abarca. É formada não apenas de volumes, mas também de cores, movimentos, odores, sons etc."

Vários autores também abordam a concepção de paisagem, para Marx (1981) em seu conceito de paisagem pressupõe aspectos de âmbito ecológico, cultural, biogeográfico e arquitetônico. Sauer (1998) considera região e área, equivalentes à paisagem, associado às diversas formas físicas e culturais. Dansereau (1949) compreende a paisagem a partir do momento que a atividade humana passa a ser considerada. Os autores trazem o conceito de paisagem que se completa, a partir da transformação entre a sociedade e a natureza, caracterizando o espaço a partir das modificações e construções de novas paisagens.

Nesta perspectiva, a paisagem pode ser analisada a partir da transformação urbana, surgindo novas características, consolidando a paisagem na produção do espaço, através de elementos do urbanismo (cidade, avenidas, ruas, casas, edifícios, comércios, indústrias etc.), dando identidade que constrói a sociedade. A paisagem assume um papel importante, tornando-a fundamental, pois a cidade e o urbano são objetos de complexidade em estudo, sendo necessária a apreensão do holístico para compreender o geral sem omitir as particularidades, visto que, como meio de produção das ações sociais, a cidade, reúne vários elementos dentro do espaço (Alves, 2010).

Neste processo de transformação, a paisagem urbana investiga ações e relações sobre a cidade a partir das transformações da natureza pelas ações humanas de modo que se apropria do espaço visível da paisagem, sendo reproduzido a história através das concepções do homem sobre o morar, o trabalhar e 0 viver (Ferreira, 2009). A paisagem de acordo Ferreira (2009, p. 64) "revela uma história, o passado inscrito nas formas geradas por diferentes tempos acumulados, sincrônicos e diacrônicos. Nesse sentido, a leitura da paisagem permite uma leitura e uma interpretação do mundo atual, revelando no visível, a história do lugar."

Nesse processo histórico a transformação da paisagem urbana, surgem novas paisagens no espaço urbano, com grandes edifícios considerados "arranha-céu", materializando na dinâmica espacial, contribuindo para acumulação e reprodução do capital no mercado imobiliário, que conforme Souza $(1994$, p. 88) "a produção de edifícios, constitui-se uma possibilidade inusitada de articulação das múltiplas formas do capital num objeto - o edifício, num mesmo lugar - 0 urbano, num tempo/circulação extremamente reduzida." 0 autor ainda acrescenta que:

"No caso da produção de edifícios, fica evidente que a penetração da técnica, associada ao surgimento de múltiplos agentes interessados nessa produção, articula-se sob formas que se vão diferenciando no tempo. E é exatamente essa diferenciação, aliada às características gerais de desenvolvimento da sociedade no espaço ou dela resultante, que vai configurar os diferentes períodos de produção do edifício, ou o processo de verticalização" (Souza, 1994 p. 88). 
Nesse processo de verticalização, o espaço urbano é apropriado pelos agentes transformadores, como mercadoria de consumo que se materializa no processo social, político, econômico e cultural, de modo desigual. É importante refletir que a transformação da paisagem urbana verticalizada irá associar a diversos conflitos sociais e ambientais. De acordo com Ramirez, (1997) e Töws \& Mendes (2007), verticalizar significa a criação de novos solos, sobreposto em lugares que a vida fique sobreposta a vários andares, que irá possibilitar abrigo, de maiores continentes, sendo valorizadas estas áreas urbanas com 0 aumento do potencial de aproveitamento.

Muitas vezes a verticalização ocorre quando há demolição ou até mesmo a substituição de antigas residências, ou edificações, sendo materializado através da anulação de referências históricas. É nesse processo de transformação da paisagem urbana que entre o novo e o moderno, a conservação e o ambiente, e a ampliação dos edifícios verticalizados vão produzindo nos espaços em detrimento das novas residências de formas horizontais.

\section{ESPAÇO URBANO DA CIDADE DO RECIFE: EXPANSÃO DA VERTICALIZAÇÃO}

A configuração da cidade do Recife foi modificada pelas transformações do espaço urbano, consequência disso é a valorização e a disputa desses espaços cada vez extintos. Na medida em que a população cresce, consequentemente a cidade necessita de novos espaços para ser ocupados e habitados.

O espaço da cidade do Recife começa a ganhar valores a partir das condições existentes, sendo geradas novas paisagens, assim complexas decorrentes dos aglomerados de baixa renda, dividindo 0 moderno do com o podre. A estruturação atual do Recife é origem das ações se acumulam ao longo dos anos (Silva, 2008). Por essa razão, configura-se a cidade com as condições inseridas diante da sociedade, uma complexidade que cresce decorrente do sistema capitalista que transforma e modifica todo o espaço urbano.

Silva (2008), ainda descreve que a cidade do Recife, iniciou seu desenvolvimento muito cedo, através de dois núcleos de moradias (Classe verticalizada e classe "inferior"), neste contexto, ocorreu maior ênfase nesses polos que contribuíram para o processo de verticalização na cidade, adotando áreas privilegiadas que contribuíram para o investimento, ou seja, quanto mais valorizado o terreno, maiores investimentos tecnológicos são investidos.

Desta maneira, os espaços urbanos são transformados e são considerados atrativos por uma classe hegemônica, criando novas fronteiras entre 0 velho e o novo, entre o podre e 0 rico, com intuito de disparidades sócio - espaciais dentro de uma única cidade, constituindo assim áreas cada vez mais nobres, decorrente da valorização do processo de verticalização. 


\section{MATERIAIS E MÉTODOS}

\subsection{Delimitação da área de estudo}

O bairro do Hipódromo está localizado na Região Política Administrativa - RPA 2, microrregião da Região Metropolitana do Recife-RMR, na cidade do Recife, em Pernambuco, com distância do Marco Zero de $3,91 \mathrm{~km}$ (Figura 01). O bairro apresenta uma área territorial de 30 (hectare) ${ }^{2}$, com uma população residente de 2. 658 habitantes (Prefeitura do Recife, 2018).

No bairro do Hipódromo, encontra-se em um terreno com divisa ao bairro de Campo Grande, composta por aproximadamente 200 casas erguidas em torno da Praça Tertuliano Feitosa (que outrora era utilizada para corrida de cavalo e atualmente é utilizada para lazer, recreação e espaço de atividades físicas) conhecidas como Vila do Hipódromo, tornou-se uma Zona Especial de Preservação do Patrimônio Histórico Cultural (ZEPH), que apresenta uma vigorosa legislação de conservação desde 1979 (Prefeitura do Recife, 2018).
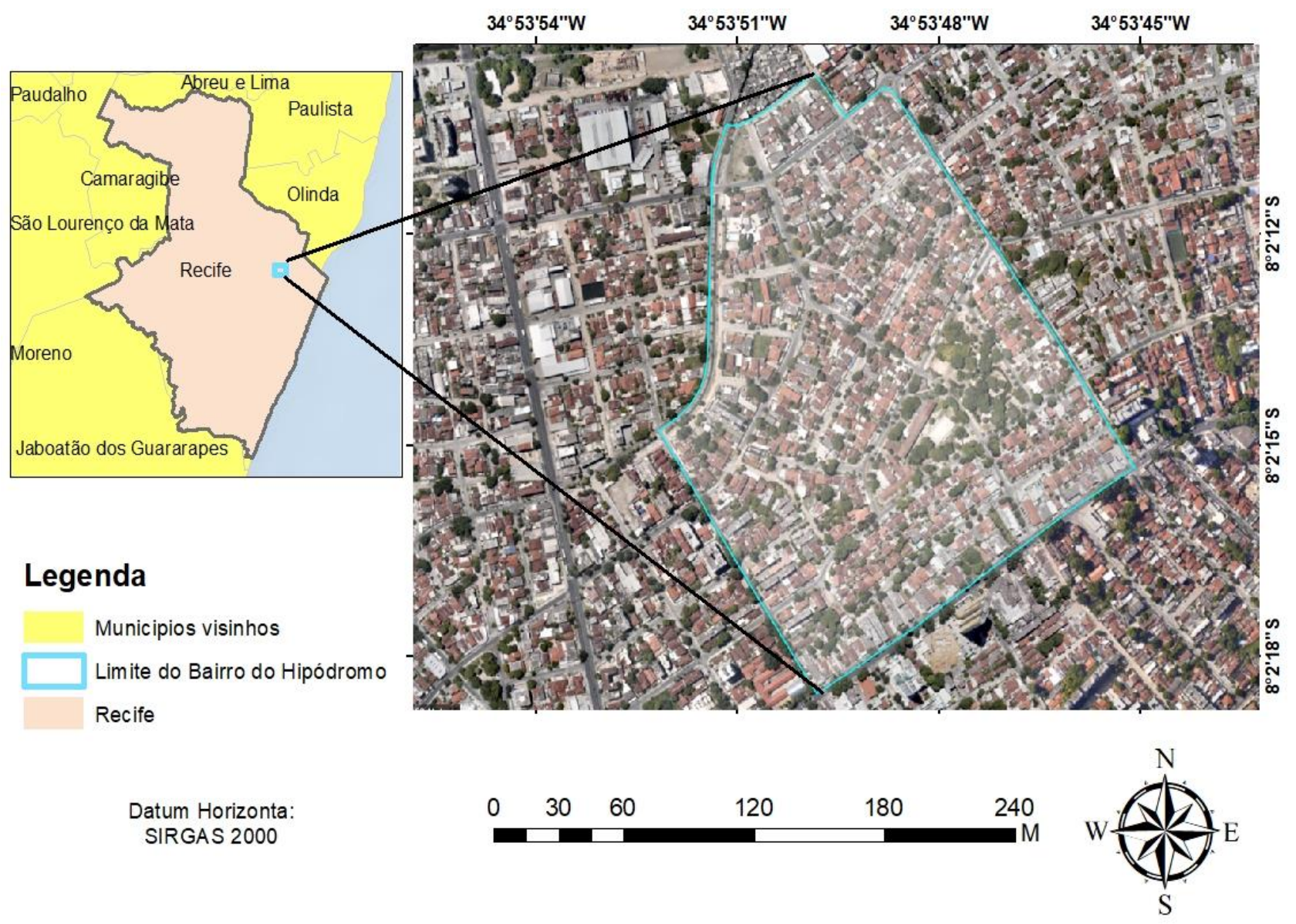

Figura 01: Mapa de localização do Bairro do Hipódromo, Município de Recife Pernambuco Fonte: IBGE (2019), adaptado Tiago Holanda (2020). 
O bairro apresenta 6.658 residentes, de acordo Prefeitura do Recife (2019), distribuídos conforme as tabelas 1, 2, 3 e 4:

Tabela 1: População residente no Bairro de Hipódromo (Recife-PE)

\begin{tabular}{|r|r|r|}
\hline \multicolumn{2}{|c|}{ POPULAÇÃO RESIDENTE POR SEXO } & $\%$ \\
\hline Masculina & 1.162 & 43,72 \\
\hline Feminina & 1.496 & 56 \\
\hline
\end{tabular}

Fonte: Prefeitura do Recife (2019), adaptada por Mesquita (2020).

Tabela 2: População por faixa etária. Bairro do Hipódromo (Recife-PE)

\begin{tabular}{|c|c|c|}
\hline POPULAÇÃO POR FAIXA ETÁRIA & HABITANTES & $\%$ \\
\hline $0-4$ anos & 112 & 4,21 \\
\hline $5-14$ anos & 283 & 10,65 \\
\hline $15-17$ anos & 116 & 4,36 \\
\hline $18-24$ anos & 262 & 9,86 \\
\hline $25-59$ anos & 1.367 & 51,43 \\
\hline 60 anos e mais & 518 & 19,49 \\
\hline
\end{tabular}

Fonte: Prefeitura do Recife (2019), adaptada por Mesquita (2020).

Tabela 3: População PR cor da pelo ou raça. Bairro de Hipódromo (Recife-PE)

\begin{tabular}{|c|c|}
\hline POPULAÇÃO POR COR OU RAÇA & $\%$ \\
\hline Branca & 65,84 \\
\hline Preta & 5,08 \\
\hline Parda & 28,59 \\
\hline Amarela & 0,41 \\
\hline Indígena & 0,08 \\
\hline $\begin{array}{l}\text { Taxa de } \\
\text { Taxa Média Geométrica de Crescimento Anual da População }\end{array}$ & e mais \\
\hline
\end{tabular}

Fonte: Prefeitura do Recife (2019), adaptada por Mesquita (2020). 
Tabela 4: Densidade Demográfica. Bairro de Hipódromo (Recife-PE)

\begin{tabular}{|c|c|}
\hline \multicolumn{2}{|c|}{ DENSIDADE DEMOGRÁFICA } \\
\hline Total por Habitante/Hectare & $88,13 \%$ \\
\hline Domicílios $\left(\mathrm{n}^{\circ}\right)$ & 808 \\
\hline Média de moradores por domicílio (Habitante/Domicílio) & 3,3 \\
\hline Proporção de Mulheres Responsáveis pelo Domicílio (\%) & $47,15 \%$ \\
\hline Valor do Rendimento Nominal Médio Mensal dos Domicílios & $\mathrm{R} \$ 4.803,91$ \\
\hline
\end{tabular}

Fonte: Prefeitura do Recife (2019), adaptada por Mesquita (2020).

\subsection{Instrumentos metodológicos}

A pesquisa seguiu os seguintes procedimentos metodológicos, para melhor compreensão foi

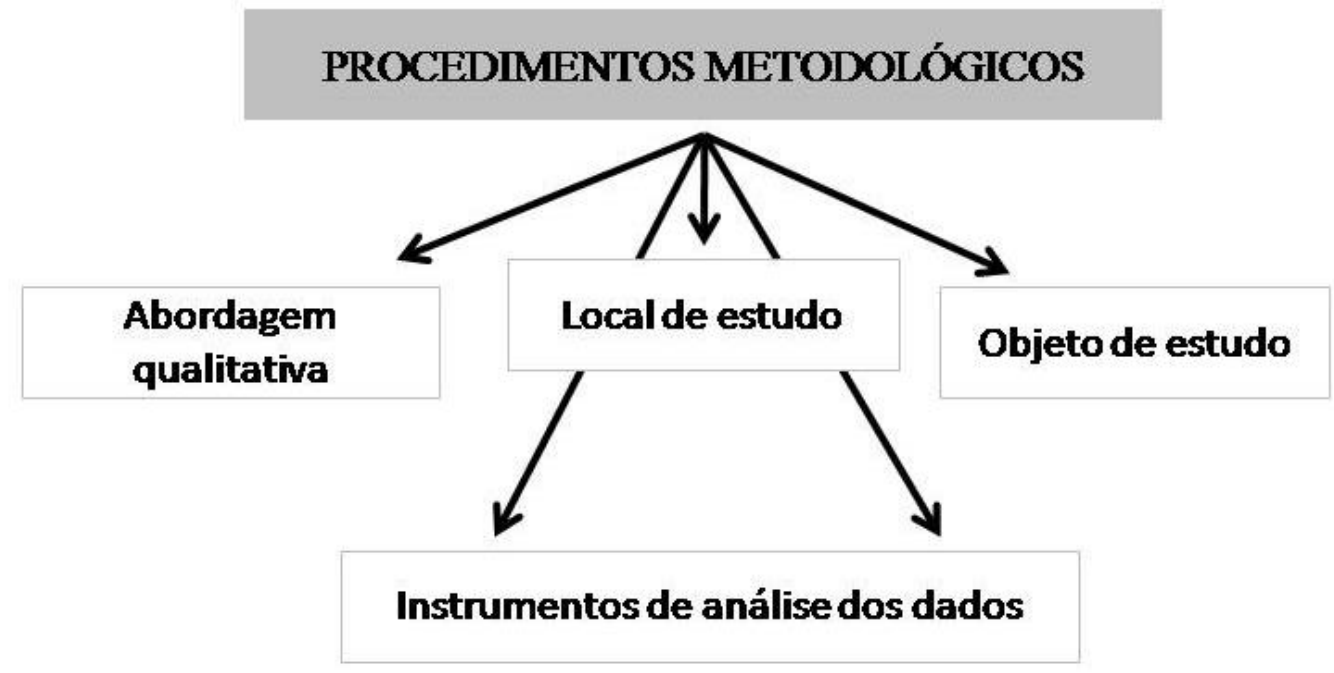

elaborado o fluxograma (Figura 2) como forma de representar o que foi realizado ao longo dessa pesquisa.

Figura 2:Fluxograma dos procedimentos metodológicos.

Fonte: Mesquita (2019).

Para realização da pesquisa, foi realizada através da abordagem qualitativa, que de acordo com Triviños (1987, p. 124), compreende que:

A pesquisa qualitativa é conhecida também como "estudo de campo", "estudo qualitativo", "interacionismo simbólico", "perspectiva interna", "interpretativa", "etnometodologia", "ecológica", "descritiva", "observação participante", "entrevista qualitativa", "abordagem de estudo de caso", "pesquisa participante", "pesquisa fenomenológica", "pesquisa-ação", "pesquisa naturalista", "entrevista em profundidade", "pesquisa qualitativa e fenomenológica", e outras [...]. Sob esses nomes, em geral, não obstante, devemos estar alertas em relação, pelo menos, a dois aspectos. Alguns desses enfoques rejeitam total ou parcialmente $o$ ponto de vista quantitativo na pesquisa educacional; e outros denunciam, 
claramente, os suportes teóricos sobre os quais elaboraram seus postulados interpretativos da realidade (Triviños, 1987, p. 124).

Portanto, a pesquisa contribui para fundamentar através da compreensão sobre o local e objeto de estudo que se complementa através dos levantamentos bibliográficos constituídos por: livros, artigos e dissertações, leis, além de sites de órgãos públicos, que consolidam a pesquisa e fundamenta a investigação.

Neste contexto foram realizadas visitas ao local de estudo para maior aproximação da realidade com o objeto de estudo e compreender as modificações e as causas pela transformação do espaço e posteriormente análise de todos os dados coletados para entender a conjuntura da dinâmica do espaço urbano diante das transformações impostas.

\section{PROCESSO DE VERTICALIZAÇÃO NO BAIRRO DO HIPÓDROMO, RECIFE - PE}

A produção do espaço urbano se desenvolve pelo processo hegemônico, que implica pelo desenvolvimento dos sistemas através dos grupos sociais e suas apropriações no ambiente e na cidade do Recife, isto não foi diferente. As mudanças nos espaços urbanos são reagentes pelo domínio de poder do capital que se concretiza a partir da especulação imobiliária, através da dominação política que moldam as relações sociais.

Neste contexto, o processo de verticalização do bairro do Hipódromo, ocorreu nas décadas de 1930 e 1940, através do conceito de "cidades jardins", devido a ocupações de árvores existentes no bairro (Figura 3). O bairro tornou-se pioneiro neste conceito em uma vila na concepção urbanística e pelas suas articulações em vincular a ideia de urbano com jardim (Figura 4, 5 e 6).

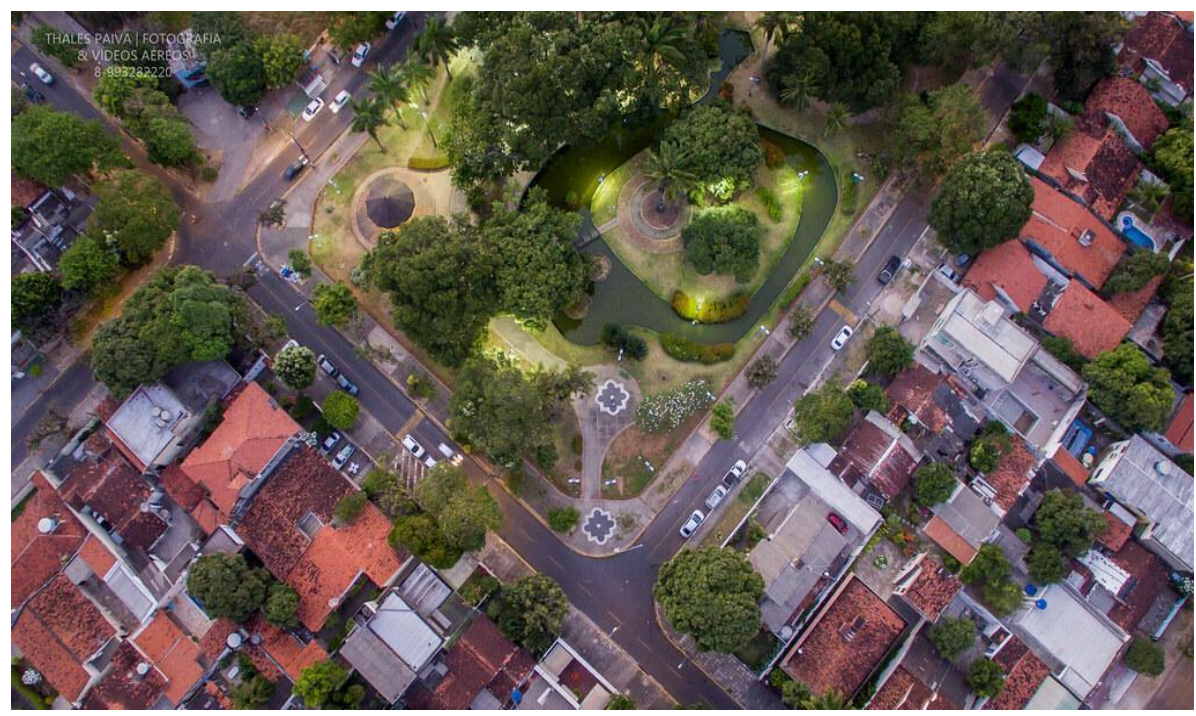

Figura 3: Bairro do Hipódromo, Recife-PE.

Fonte: Thales Paiva (2019). 

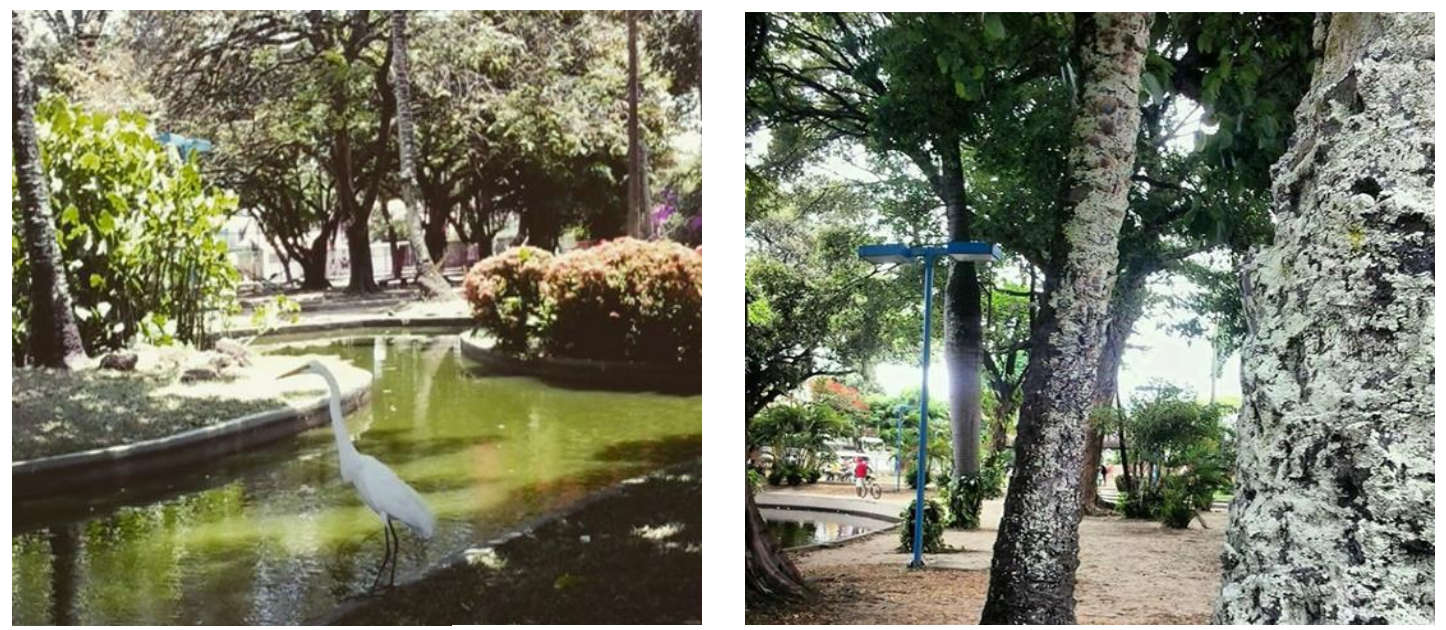

Figura 4 e 5: Recorte da Praça Tertuliano Feitosa, presença da fauna e flora dentro do espaço urbano Fonte: Mesquita (2019).

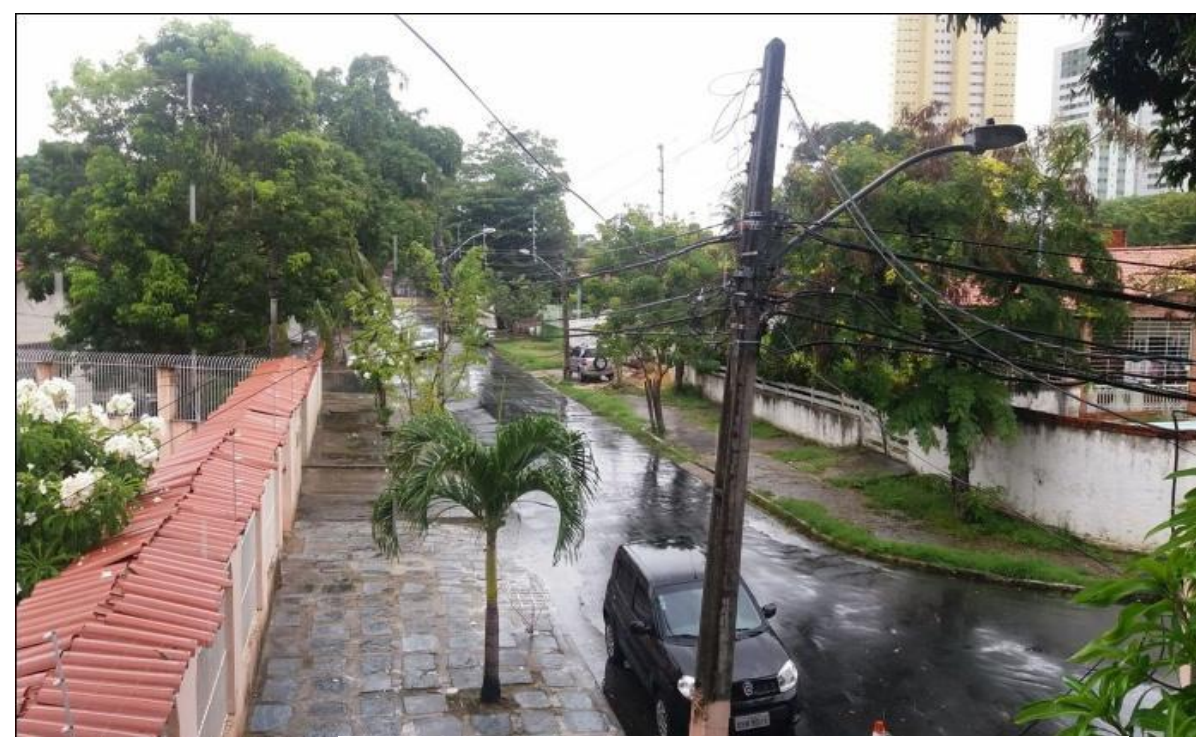

Figura 6: Casas e vestígios de área verde no Bairro do Hipódromo Fonte: Mesquita, (2020).

A Lei Municipal de Preservação dos Sítios Históricos da cidade do Recife (Lei n 13. 957), instituída em setembro de 1979, aprovada pelo Governo do Estado, na qual tem a pauta voltada a preservação do planejamento urbano da cidade, pela qual o bairro do Hipódromo, encontra-se inserido, com os principais conceitos de áreas de interesse sendo conservada. Nesta Lei define normas gerais de proteção que estabelece zonas especiais de patrimônio construído (Recife, 1979). Em 1996, com Lei № 16.176, que estabelece diretrizes para uso e ocupação do solo na cidade do Recife, passou a caracterizar os sítios históricos através do qual protege as características arquitetônicas ou tipologia que define os conjuntos urbanos, reunidas em uma única ZEPH (Recife, 1996).

Em algumas visitas in loco, no período de fevereiro/março de 2018 e dezembro/2019, pode-se observar que a manutenção das características das residências urbanas no bairro do Hipódromo, encontra-se conforme a lei mencionada, porém em algumas ruas inseridas no bairro, encontram-se edifícios antigos e outros sendo construídos com estrutura moderna de "arranha-céu" (Figura 7 e 8). 


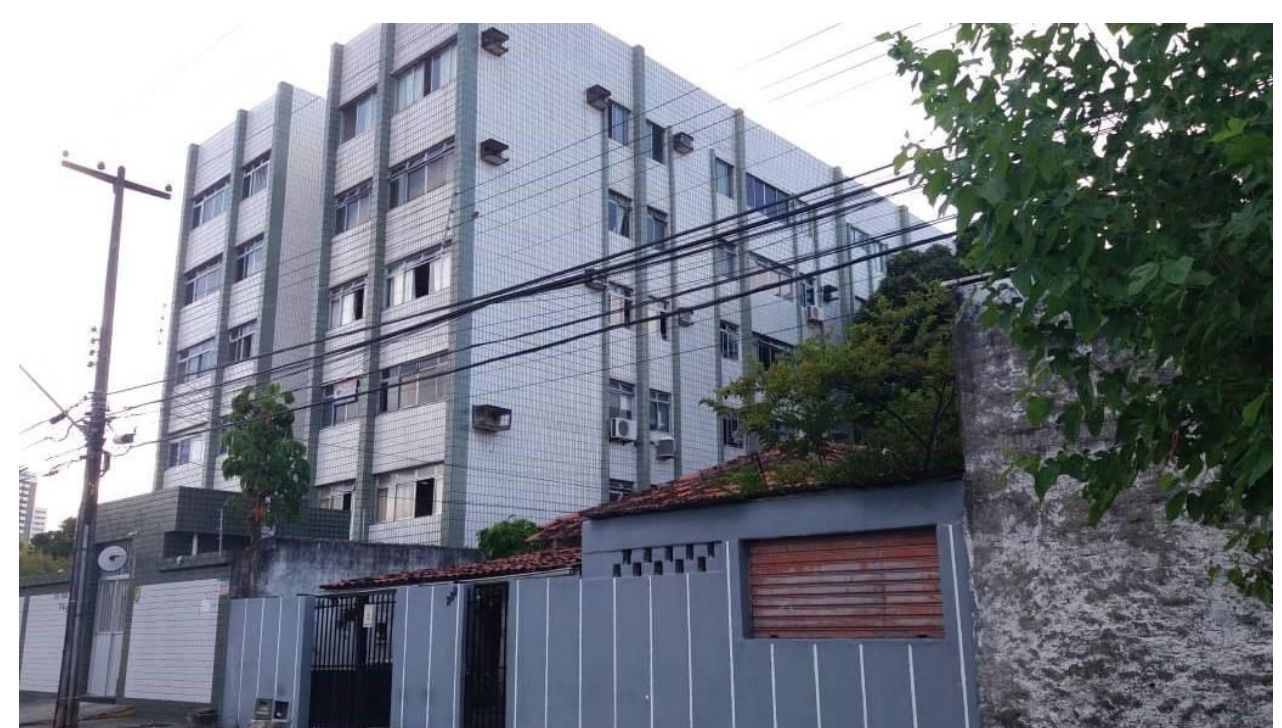

Figura 7: Edifício antigo construído próximo às casas.

Fonte: Mesquita (2020).

Neste sentido, nota-se o processo de verticalização urbana apresentando inúmeras transformações no bairro e mudando sua conjuntura estrutural e simbólica. Tais características são vinculadas ao processo de transformação do espaço urbano, que abarca a necessidade do sistema de produção capitalista, sendo vinculado pelo valor de interesses econômicos que é oferecido no bairro do Hipódromo por apresentar uma boa localização e ambientes arborizados, além do crescimento populacional da cidade do Recife, na qual se tornou complexa a sua expansão. 0 processo de verticalização no bairro iria mudar toda a conjuntura produzida pelo contexto da realidade espacial da região, além de sua "tradicionalidade", como uma vila de moradores.

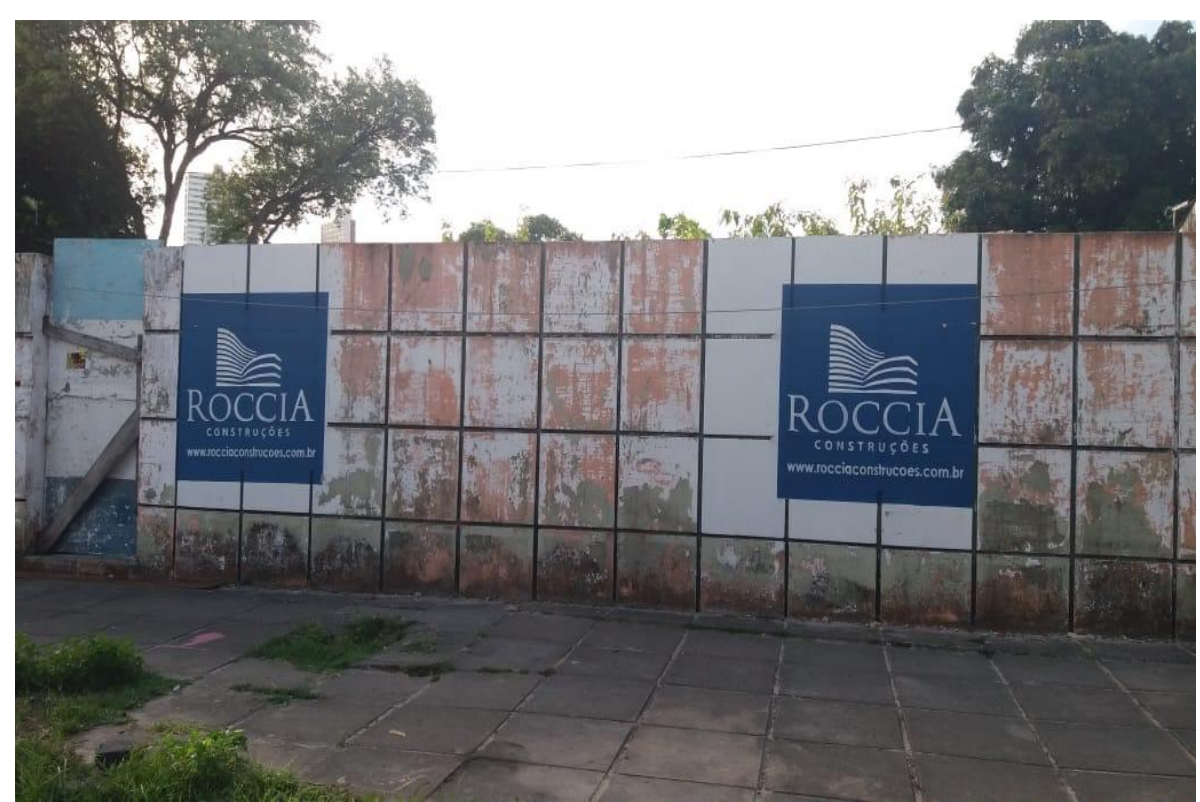

Figura 8: Casas foram demolidas para construção de edifícios no Bairro do Hipódromo. Fonte: Mesquita (2020).

De acordo com a "Lei dos 12 bairros", ficam vedadas tais construções de edifícios e prédios no bairro. Por essa razão, deve ser protegido por órgãos públicos, em transparência com a sociedade civil, apesar de 
que em seu entorno teve uns aumentos significativos de construção, mas até o momento o bairro está sendo conservado com sua natureza arquitetônica de residências baixas, valorizando o bairro e controlando as construções imobiliárias do bairro., portanto é necessários estudos destinados aos bairros que apresentam Leis de conservação de suas estruturas, para preservação desses ambientes que apresenta uma tradição histórica e vegetação.

O processo de verticalização urbana provocou inúmeras transformações nas grandes cidades brasileiras, sendo necessária uma nova dinâmica para a estruturação urbana, pela própria conjuntura espacial, tornando necessários novos investimentos no padrão da qualidade de vida da população.

Os Agentes imobiliários atuantes no mercado econômico visam às áreas que apresentam condições de áreas existentes para empreender, neste caso, essas ações são ocasionadas onde existem propostas de condições de vida favorável, sendo concentrado para um tipo de público com poder aquisitivo que visem nestas possibilidades habitar, contribuindo para busca e a oferta no mercado imobiliário por grandes arranhas céus.

$\mathrm{Na}$ cidade do Recife, de acordo com seu histórico e a própria legislação do centro urbano, não foi construída limites de altura para a produção de edificações, mas incentivou desenvolver a verticalização, com maiores prédios, na qual as diretrizes propostas na Lei $\mathrm{N}^{0} 16.176 / 96$ passou a ser implantado como parâmetro necessário no desenvolvimento dessas construções (Recife, 1996). Com a saturação dos espaços tradicionais ocupados, a cidade do Recife não tem para onde crescer, sendo necessário verticalizar os espaços já ocupados, por bairros tradicionais, para exploração dessas áreas do processo de ocupação em busca de lucro e geração de capital.

\section{CONSIDERAÇÕES FINAIS}

Diante das transformações dentro do espaço urbano, o bairro do Hipódromo é atualmente palco de interesses econômicos e estruturais, decorrentes do grande crescimento da cidade do Recife, tornando-se complexo a expansão, já que existem leis que veta o processo de verticalização do bairro, pois iria mudar toda a conjuntura social e histórica, produzida pelo contexto da realidade espacial do bairro, além de sua "tradicionalidade", como uma vila de moradores.

A "Lei dos doze bairros" veta tais construções de edifícios e prédios no bairro do Hipódromo. Por essa razão, deve ser protegido por órgãos públicos, em transparência com a sociedade civil, apesar de que em seu entorno teve um aumentos significativos de construção, em especial o bairro de Campo Grande que vem crescendo com fortes empreendimentos imobiliários, mas até 0 momento 0 bairro está sendo conservado com sua natureza arquitetônica de residências baixas, valorizando o bairro e controlando as construções imobiliárias do bairro., portanto é necessário estudo destinados aprofundados aos bairros que apresentam 
Leis de conservação de suas estruturas, para preservação desses ambientes que apresenta uma tradição histórica e ambientes naturais.

Contudo, é notório que os agentes imobiliários visem aquele espaço de investimentos futuros para a expansão imobiliária, sendo observado nos arredores grandes construções de novos edifícios, consequentemente, modificando as relações sociais, ambientais e paisagísticas da área, e deixando de existir um ambiente que tem história e uma relação de bem-estar.

Por essa razão, a pesquisa tornou-se possível analisar a verticalização de forma lenta, mas aparente, no bairro do hipódromo, buscando maior valorização do ambiente que apresentam a conservação do espaço

\section{REFERÊNCIAS}

Alves, L. A. (2010). Representações das transformações espaciais: breves considerações sobre a paisagem urbana. Para Onde!?, v. 4, n. 1. DOI: https://doi.org/10.22456/1982-0003.22109

Barbosa, V. L., \& Júnior, A. F. N. Paisagem, ecologia urbana e planejamento ambiental. (2009). Geografia (Londrina). v. 18, n. 2. DOI: http://dx.doi.org/10.5433/2447-1747.2009v18n2p21

Carlos, A. F. A. (2013). A cidade - O homem e a cidade, a cidade e o cidadão, de quem é o solo urbano?. São Paulo: Contexto.

Carlos, A. F. A. (2011). A condição espacial. São Paulo: Contexto.

Dansereau, P. (1949). Introdução à biogeografia. Separata de: Revista Brasileira de Geografia, Rio de Janeiro: Instituto Brasileiro de Geografia e Estatística, Conselho Nacional de Geografia, n. 1. Recuperado de: https://biblioteca.ibge.gov.br/visualizacao/periodicos/11 5/rbg_1949_v11_n1.pdf

Ferreira. L. R. (2009). Transformações na Paisagem Urbana de Santa Vitória do Palmares-RS: Relações sociais, políticas de habitação e a produção da cidade. (Dissertação de Mestrado em Geografia). Recuperado de:

https://www.lume.ufrgs.br/bitstream/handle/10183/1797 7/000727023.pdf?sequence $=1$.

Gomes, E. T. A., \& Albuquerque, M. Z. A. (2013). A Via Mangue no processo de produção do espaço da cidade do Recife. Anais do X ENANPEGE.

Lefebvre, H. Espaço e Política. (2008). Belo Horizonte: Ed. UFMG.
Lima, L. G., \& Conceição, A. L. (2010). A produção do espaço e da escala pelo capital. Contra a Corrente. n. 3. Recuperado de:

https://gpect.files.wordpress.com/2013/11/aproduc3a7c3a3o-do-espac3a7o-e-da-escala-pelocapital.pdf.

Mazzei, K., Colesanti, M. T. M., \& Santos, D. G. (2007). Áreas verdes urbanas, espaços livres para o lazer. Sociedade \& Natureza. v. 19, n. 1, p. 33-43.

Recuperado de:

http://www.seer.ufu.br/index.php/sociedadenatureza/arti cle/view/9350.

Maricato, E. (1982). A Produção Capitalista da Casa (e da Cidade) no Brasil Industrial. São Paulo: Ed. AlfaÔmega.

Marx, B. R. (1981). Ecologia e paisagismo. São José do Rio Preto: Unesp.

Marx, K. (2008). O capital: crítica da economia política. Rio de Janeiro: Civilização Brasileira.

Mendonça, F. (2004). O Sistema Socioambiental Urbano: uma abordagem dos problemas socioambientais da cidade. In: Mendonça, F. (org.) Impactos Socioambientais urbanos. Curitiba: Editora UFPR

Prefeitura do Recife. (2018). Hipódromo. Recuperado de:

http://www2.recife.pe.gov.br/servico/hipodromo?op=Nz $\mathrm{Q} 1 \mathrm{NQ}==$

Ramirez, J. C. L. (1997). A verticalização de São Paulo e o cinema: uma nova dimensão nos estudos da cidade. Sociedade e Natureza. n. 9, p. 5-22. 
Recife. (1996). Lei n. 16.176/96. Estabelece a lei de uso e ocupação do solo da cidade do Recife.

Recife. (1979). Lei .13.957/79.Institui normas gerais de proteção a sítios, conjuntos antigos, ruínas e edifícios isolados, cujas expressões arquitetônicas ou históricas tenham real significado para o patrimônio cultural da cidade do recife; disciplina a preservação desses bens, autoriza o prefeito a declarar zonas especiais de interesse dessa preservação cultural e, dá outras providências.

Santos, M. (2004). A natureza do espaço: técnica e tempo, razão e emoção. São Paulo: EDUSP.

Santos, M. A. (2001). Técnica espaço tempoGlobalização e meio técnico científico-informacional. São Paulo: EDUSP.

Sauer, C. O. (1998). A morfologia da paisagem. In: Corrêa, R. L., \& Rosendahl, Z. (Org.). Paisagem, tempo e cultura. Rio de Janeiro: EDUERJ.

Silva, L. H. (2008). A verticalização do espaço urbano: o caso do bairro do Prado - Recife/PE. (Dissertação de Mestrado em Geografia).

Smith, N. (1988). Desenvolvimento Desigual natureza, capital e a produção do espaço. Rio de Janeiro: Bertrand Brasil.

Souza, M. A. A. (1994). A identidade da metrópole: a verticalização de São Paulo, Edusp.

Töws, R. L., \& Mendes, C. M. (2007). Verticalização x legislação na Avenida Brasil em Maringá-PR no período de 1960-2004: algumas considerações. Recuperado de: http://www.vitruvius.com.br/arquitextos/arq000/esp410. asp.

Triviños, A. N. S. (1987). Três enfoques na pesquisa em ciências sociais: o positivismo, a fenomenologia e 0 marxismo. In: Introdução à pesquisa em ciências sociais. São Paulo: Atlas, p. 3.

Uriarte. U. M., \& Carvalho, M. J. F. (2014). Avenida Sete e seus transeuntes (parte 1). In: Uriarte, U.; Carvalho, F.; Milton, J. (Org.). Panoramas urbanos: usar, viver e construir Salvador. Salvador: Edufba, $p$. 31-58. 